Addendum

\title{
Addendum: Shqair, M., et al. Analytical Solution for Multi-Energy Groups of Neutron Diffusion Equations by a Residual Power Series Method. Mathematics $2019,7,633$
}

\author{
Mohammed Shqair ${ }^{1, *} \mathbb{0}$, Ahmad El-Ajou ${ }^{2}\left(\mathbb{D}\right.$ and Mazen Nairat ${ }^{3}$ \\ 1 Physics Department, Faculty of Science and Humanities, Prince Sattam bin Abdulaziz University, \\ Al-kharj 11942, Saudi Arabia \\ 2 Department of Mathematics, Faculty of Science, Al Balqa Applied University, Salt 19117, Jordan; \\ ajou42@yahoo.com \\ 3 Department of Physics, Faculty of Science, Al Balqa Applied University, Salt 19117, Jordan; \\ mazens@bau.edu.jo \\ * Correspondence: shqeeeer@gmail.com; Tel.: +966-59-6498633; Fax: +966-11-5888001
}

Received: 29 October 2019; Accepted: 3 November 2019; Published: 5 November 2019

The authors wish to insert this additional sentence in the Acknowledgments section [1]:

"The financial support of the project (Using New Mathematical Methods in Solving Neutron Diffusion Equations in Bare and Reflected Nuclear Reactors) funded by the Deanship of Scientific Research at Prince Sattam Bin Abdulaziz University within the Specialized Research Grant program and under contract number 2017/01/7676 is gratefully acknowledged."

The authors would like to apologize for any inconvenience caused to the readers by these changes. The changes do not affect the scientific results. The manuscript will be updated and the original will remain online on the article webpage, with reference to this Addendum.

Conflicts of Interest: The authors declare no conflicts of interest.

\section{References}

1. Shqair, M.; El-Ajou, A.; Nairat, M. Analytical Solution for Multi-Energy Groups of Neutron Diffusion Equations by a Residual Power Series Method. Mathematics 2019, 7, 633. [CrossRef]

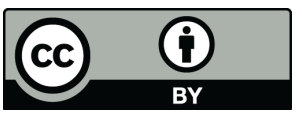

(C) 2019 by the authors. Licensee MDPI, Basel, Switzerland. This article is an open access article distributed under the terms and conditions of the Creative Commons Attribution (CC BY) license (http://creativecommons.org/licenses/by/4.0/). 